\title{
, CORRESPONDENCE
}

\author{
Inadequate prenatal diagnosis of \\ Down's syndrome \\ R Harris, FRCP . . . . . . . . . . . . . . . . . 199 \\ Hazards of epilepsy \\ J B Wilson, FRCPED \\ Spontaneous abortion and fetal \\ abnormality in subsequent pregnancy \\ A J Gardiner, $M B$, and others.......... \\ Adjuvant chemotherapy in T3 bladder \\ cancer \\ B Richards, frcs............ 200 \\ Thyroid extract \\ W van't Hoff, FRCP, and others. \\ Living with artificial valves \\ J R Belcher, fRCS. . . \\ Uniform style for biomedical journals \\ Maeve O'Connor, BA; G Tevaarwerk,

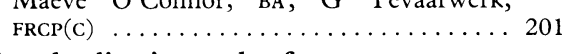 \\ Standardisation and safety \\ K B Thomas, FFARCS \\ Drug treatment card \\ I G Tait, FRCGP. . \\ Oesophagitis as a side effect of \\ emepronium \\ R H Higson, FRCS. \\ Genital infections and cervical \\ carcinoma \\ B Astedt, MD, and others. . . \\ Epidemic myalgic encephalomyelitis \\ Celia B M Wookey, MB. \\ Leukostasis in chronic myeloid \\ leukaemia \\ D S Thompson, MRCPATH, and others... . 202 \\ Treatment of ulcerative colitis
}

A G Ironside, FRCPED, and others...... 202
Spontaneous remission of nephrotic

syndrome in amyloidosis

J-P Méry, MD.

Snakes and snake bite

J-J Brossy, FRCS; M J Gilkes, FRCS . . . . . . 203

Alcohol and the blood

D M Chalmers, MRCP, and others...... 203

Nutrition and the brain

B H Kirman, FRCPSYCH............ 203

Factors affecting length of hospital stay

R Hole, FRCS. .

Effects on fetus of stillboestrol in

pregnancy

Valerie Hartley-Brewer, $\mathrm{MD}$

Inappropriate use of tricyclic

antidepressants

J R Kirwan, $M B$.

"Innovation in the Pharmaceutical

Industry"

$T$ B Binns, FRCP.

Utility of needle aspiration of tumours

P A Trott, MRCPATH

Factors influencing the incidence of

neonatal jaundice

Louise Friedman, BSC, and others... . . . . 204

Non-epileptic television syncope

D M B Hall, MRCP . . . . . . . . . . . . . . 205

Lymphatic fistula: a complication of arterial surgery

R J Croft, FRCS.

Windows in operating theatres

T K Hardy, fFarCs............... 205

Myelography and epidural double-

catheter venography

G C H Meijenhorst, MD

Chloroquine resistance in Zambia

L J Bruce-Chwatt, FRCP.......... 206
PUVA or dithranol ?

$M$ Whitefield, PHD

Where are the untreated depressives?

G H Jones, MrCPSYCH............. 206

Carcinoma of the male breast and

oestrogen metabolism

D A L Morgan, MB, and Anne Hong, MB . . 206

Confidentiality of medical records

A O Staines, MB; Patricia Martin, MB ..... 206

The principle of coterminosity and the

NHS

E Wilson Jones, FRCP.

General practice records

J T Hart, FRCGP.

Out-of-hours use of clinica

pathologists.............

Registrar redistribution

G I B Da Costa, FrCSED.

New consultant contract

W J Harrison, FRCPATH.

Future of British anaesthetics

A solution for preclinical departments

J Moroney, FRCS; W S Monkhouse, MB . . . 208

tem-of-service payments to general

practitioners

J P H Anderson, BM . . . . . . . . . 208

Unfinished business

R E Steel, FRCGP.

208

oints Use of penicillins (A A Robertson);

Thirty years ago (F E S Hatfield); Support for

families bereaved by cot death (D McCarthy;

$\mathrm{T}$ Mulvey); How much physical therapy for

patients with stroke? (A J Akhtar, and W M

Garraway) ................... 209

Correction: Family health services

Williams $\ldots \ldots \ldots \ldots \ldots \ldots \ldots \ldots \ldots 209$
Correspondents are urged to write briefly so that readers may be offered as wide a selection of letters as possible. So many are being received that the omission of some is inevitable. Letters must be signed personally by all their authors.

\section{Inadequate prenatal diagnosis of Down's syndrome}

SIR,-This letter is written because a local 40 -year-old trained nurse has recently been delivered at term of a liveborn infant with Down's syndrome even though she had early amniocentesis at 16 weeks' gestation. Culture failure due to poor laboratory conditions and excessive work load can be blamed. This is not an isolated example and similar ones will occur in the future because demand from women informed and alarmed by the media threatens to swamp available resources. Ultrasonic scanning facilities are overloaded (Dr B M Gompels, 3 June, p 1487) and there are relatively few obstetricians in a position to perform amniocentesis, while amniotic cell chromosome analysis is time consuming so that trained cytogeneticists cannot cope with more than 150-200 cultures per year.

Ferguson-Smith ${ }^{1}$ and others have commented on the high frequency of chromosomally abnormal fetuses at the time of early amniocentesis in older women, perhaps an accurate reflection of an unexplained increase in the frequency of Down's syndrome among the newborn. ${ }^{2}$ Chromosome aberrations are found in $0 \cdot 6-1.5 \%$ of fetuses at maternal age $35-39$ and in at least $5 \%$ of women of 40 and over. Thus, prenatal screening for Down's syndrome with termination of affected pregnancies becomes increasingly cost effective with maternal age, the break-even point being about 35 years. $^{3}$ Other indications for early amniocentesis include a previous pregnancy involving Down's syndrome or neural tube defect and a persistently high maternal serum $\alpha$-fetoprotein concentration in the present pregnancy. With due allowance for women who wish to opt out, obstetricians should be able to offer prenatal diagnosis at least to women with these high risks, whereas at present many have to be turned away. When facilities are available only the highest clinical and laboratory standards are acceptable since the choice of abortion in a wanted pregnancy already advanced to 20 weeks is a life-and-death decision unique in medicine, while the avoidable birth of a child with Down's syndrome or open crippling spina bifida is an obvious and distressing event. Sadly, within some centres resources may not be available to allow such high standards, although this problem may be obscured by a lack of follow-up of pregnancies submitted for prenatal diagnosis and pronounced normal, so that "false-negative" laboratory errors may be missed. Further, if amniocentesis does cause some increase in fetal loss and of perinatal problems this will not be apparent unless follow-up at a local level is a routine procedure. Regrettably, preamniocentesis counselling may not always be adequate and an individual woman may not be given sufficient comprehensible information to decide for herself whether the rewards of amniocentesis are commensurate with the risk. Finally, support from health visitors and others is essential during this difficult phase of a woman's life.

For both humane and economic reasons adequate moneys should be made available to properly designated regional genetic centres associated with expert obstetrics and sonar for amniocentesis. Some means must also be found to circumvent the present doctrine of devolution within the Health Service, since regional services sometimes compete un- 
successfully for resources within district or area.

If prenatal diagnosis has to be done, let us at least do it properly.

RODNEY HARRIS

Department of Medical Genetics,
St Mary's Hospital, Manchester

${ }_{1}^{1}$ Ferguson-Smith, M A, Lancet, 1976, 2, 252. 2 Evans, J A, Hunter, A G W, and Hamerton, J L,
fournal of Medical Genetics, 1978, 15, 43.

Hagard, S, and Carter, F A, British Medical fournal, 1976, 1, 753 .

\section{Hazards of epilepsy}

SIR,-I was interested to read your leading article on this subject ( 3 June, p 1436), especially that section in which you state that "from the infrequency of reports of death during sleep apparently due to suffocation during a fit the hazard may be presumed rare-especially in comparison with the frequency of nocturnal fits in children. Even so, substitution of a firm pillow might be a wise safeguard."

This statement is certainly contrary to the conclusions drawn by my colleague $\mathrm{Dr}$ H J A Longmore and myself in 1970, when three patients with grand mal epilepsy who had died by suffocation in their pillow were reported. ${ }^{1}$ This article stimulated the reply from Dr C Worster-Drought ${ }^{2}$ on which was based the comment referred to above. Dr Worster-Drought had, during his 45 years as a neurologist in Harley Street, seen no such cases and considered them uncommon.

My own view is that such tragic deaths are not so uncommon and that most of them occur in the home so that their frequency is not generally appreciated-certainly not by consultant neurologists. To emphasise the need for patients with grand mal epilepsy to use smother-proof pillows a further letter was written in 1973 describing two further cases which had occurred in Dumfriesshire within a 10-year period." Should this incidence be typical of the rest of the country this would mean that 20 cases would occur in Scotland each year-no negligible number. An article from Denmark ${ }^{4}$ helps to bear out my contention. The number of deaths in epilepsy was found to be increased in the fourth and fifth decades by 413 and $558^{\circ}$, respectively.

From my own findings and from the fact that six other cases have come to my notice since the publication of our original article (the latest, reported in the Bury Times on 6 January this year, described an epileptic who had suffocated in his pillow during a fit, this time in hospital with the diagnosis verified at post-mortem examination) I would suggest, contrary to the statement in your leading article, that many deaths in younger epileptics do occur from suffocation during a fit.

JOHN WILSON

Lockerbie, Dumfriesshire

${ }^{1}$ Longmore, H J A, and Wilson, J B, Lancet, 1970,

2, 782 .
2 Worster-Drought, C, Lancet, 1970, 2, 876.

3 Wilson, J B, British Medical fournal, 1973, 2, 173. Henriksen, P B, et al, Acta Neurologica Scandinavica,
1967, 43, suppl 31, p 164 .

\section{Spontaneous abortion and fetal} abnormality in subsequent pregnancy

SIR,-In his criticism of our paper (22 April, p 1016) Dr W H James (27 May, p 1417) misrepresents one point and ignores another.
Firstly, he states that in so far as the malformations in our index cases were anencephaly or spina bifida $(A S B)$ (our italics) we interpreted the data as favouring the "rest" hypothesis. This is quite untrue, the whole point of our paper being to report that in the 256 index cases, where the last pregnancy had ended in a spontaneous abortion there was a statistically significant increase in congenital malformations involving several different systems as compared with controls. Our summary concluded: "This may possibly be explained by the trophoblastic 'rest' hypothesis and suggests that spontaneous abortions are more relevant to congenital abnormalities than has been thought." As stated in our paper, it seems to us highly improbable that each previous abortion was affected by the same abnormality but to a more lethal degree.

Secondly, he ignores the findings in our earlier paper in which we reported that mothers of ASB babies were significantly more likely to have had either a spontaneous abortion or a stillbirth immediately before than immediately after the abnormal baby ("middle child" effect). Agreed that it is unknown whether the spontaneous abortions were themselves ASB conceptuses, but it is certain that the stillbirths were not, because, in the series we studied, where they were so affected this was recorded and we then used them as index cases. This was also referred to in our recent paper, but was not mentioned by Dr James either in his letter to you or in his earlier paper."

A way of testing the "rest" hypothesis has been suggested to us by Professor K D Bagshawe. He thought it might be profitable to investigate for congenital abnormalities the subsequent pregnancies of women who have had a hydatidiform mole, because in this condition it is known that "rests" sometimes occur, and their presence is indicated by high human chorionic gonadotrophin levels. One of us (JC) has started to look at Professor Bagshawe's data and the survey seems to us a much more practical proposition than that pu forward by Dr James in his letter.

Ormskirk General Hospital,

A J GARDINER

Ormskirk, Lancs

Cyril a Clarke JENNIFER COWEN

R FINN

University of Liverpool,

Liverpool

O M MCKENDRICK

Liverpool School Health Service,

Liverpool Corporation, ' Clarke, C A, et al, British Medical fournal, 1975, 4,
743. W H, British Medical fournal, 1978, 1, 72.

\section{Adjuvant chemotherapy in T3 bladder}

\section{cancer}

SIR,-Two-thirds of patients diagnosed as having $\mathrm{T} 3$ bladder cancer die within three years, whether they are treated by surgery, radiotherapy, ${ }^{2} 3$ or the combination. ${ }^{3}$ More than half of those dying within this period do so as the result of metastases which were not evident at the time of diagnosis. The possibility of decreasing this mortality by attacking the micrometastases which must be present at the time of diagnosis in many patients is attractive.

Adjuvant chemotherapy has been strongly advocated by Prout ${ }^{4}$ and DeKernion, ${ }^{5}$ and a toxicity study recently carried out by the
Yorkshire Urology Cancer Research Group on 18 patients has shown that the morbidity of a combination of radical radiotherapy with doxorubicin (Adriamycin) and 5-fluorouracil is acceptable." The two-year survival figures for these patients are now available and will be presented to the plenary session of the European Organisation for Research into the Treatment of Cancer on 27 June. The numbers involved are small, but the survival figures are much better than were expected and justify a randomised prospective study to find out whether adjuvant therapy is advantageous.

Such a trial is now in progress and 46 patients have been entered so far. It is clearly desirable to complete this study as soon as possible, and it would be appreciated if anyone interested would contact $\mathrm{Mr}$ Brian Richards, Department of Urology, York District Hospital, Wigginton Road, York YO3 $7 \mathrm{HE}$, for further information.

BRIAN RICHARDS

PHILIP SMITH

Robin Glashan

M R G RoBINSON

York

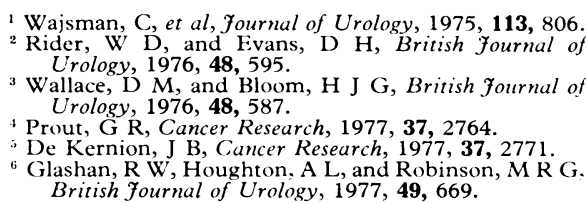

\section{Thyroid extract}

SIR,-We write to suggest that thyroid extract (Thyroid, $B P$ ) be removed from the British Pharmacopoeia and that its manufacture be abolished.

We continue to see patients who have been diagnosed as having myxoedema and who are being treated with apparently adequate doses of thyroid extract but who are clinically and biochemically hypothyroid. They have subsequently responded to thyroxine.

Although it is never possible to be certain that drugs prescribed are being taken, there is good evidence that the potency of thyroid extract is variable and its shelf-life dated. As both active constituents, thyroxine and triiodothyronine, have been available for many years we see no reason for the retention of thyroid extract, which we consider to be dangerous.

$$
\begin{array}{r}
\text { W VAN'T HOFF } \\
\text { R HOFFENBERG } \\
\text { D R LONDON } \\
\text { R HALL } \\
\text { G F JOPLIN }
\end{array}
$$
J S STAFFURTH DAVID C ANDERSON J JENKINS R L HIMSWORTH Peter SONKSEN

\section{Martindale: The Extra Pharmacopoeia, ed A Wathe, 27th edn, p 1509. London, Pharmaceutical Press}

\section{Living with artificial valves}

SIR,-I write to concur with the policy outlined in your leading article (10 June, p 1505) stressing the advantages of an imperfect natural mitral valve over those of an artificial one of whatever type.

I have been preaching the policy of conservation of the mitral valve wherever possible for the last 13 years ${ }^{1}$ starting at the time when the enthusiasm for valve replacement was at 